\title{
Small-interfering RNA-mediated silencing of the MAPK p42 gene induces dual effects in HeLa cells
}

\author{
JING-YI YUAN ${ }^{1,2^{*}}$, LI-YING LIU ${ }^{1 *}$, PEI WANG ${ }^{1}$, ZONG-FANG LI $^{2}$, LEI NI $^{1}$, \\ AIYING WANG ${ }^{1}$, SHENG-XIANG XIAO ${ }^{1,2}$, TU-SHENG SONG ${ }^{1}$ and CHEN HUANG ${ }^{1}$ \\ ${ }^{1}$ Department of Genetics and Molecular Biology, Medical School of Xi'an Jiaotong University/Key Laboratory of \\ Environment and Genes Related to Diseases, Xi'an Jiaotong University, Ministry of Education, Shaanxi 710061; \\ ${ }^{2}$ Second Affiliated Hospital, Medical School of Xi'an Jiaotong University, Shaanxi 710004, P.R. China
}

Received December 4, 2009; Accepted May 6, 2010

DOI: 10.3892/ol_00000114

\begin{abstract}
The genesis and progression of cervical cancer involve the mutation or deviant expression of numerous genes, including the activation of oncogenes (Ha-ras, C-myc, $\mathrm{C}$-erbB2 and $\mathrm{Bcl}-2)$ and inactivation of tumor-suppressor genes (p53 and Rb). Previous studies showed that small-interfering RNAs (siRNAs) targeting the MAPK p42 gene partly inhibit proliferation and increase apoptosis in human cervical carcinoma HeLa cells. Results of a microarray analysis showed that MAPK p42 siRNA inhibited cell growth through the regulation of cell cycle control and apoptosis and induced interferon-like response in HeLa cells. In order to confirm the dual effects of MAPK p42 siRNA, we compared the roles of siRNA and U0126, an inhibitor of MAPK p42, in HeLa cells. Short 21-mer double-stranded/siRNAs were synthesized to target MAPK p42 mRNA in HeLa cells. The siRNAs were transfected into HeLa cells using Lipofectamine. The cells were treated with siRNA or U0126 at different concentrations for a period of $48 \mathrm{~h}$. The biological effect of siRNA and U0126 on HeLa cells was measured by MTT and flow cytometry. MAPK1, NUP188, P38, STAT1, STAT2, PML and OAS1 were analyzed by real-time quantitative PCR. HeLa cell growth was inhibited by siRNA or U0126, and the effect of siRNA inhibition was greater than that of U0126. Cell cycle phases were different for siRNA or U0126, but HeLa cell growth was arrested at the $\mathrm{S}$ phase by siRNA and at G1 phase by U0126. A down-regulation in MAPK p42 expression by
\end{abstract}

Correspondence to: Dr Chen Huang, Department of Genetics and Molecular Biology, Medical College of Xi'an Jiaotong University/ Key Laboratory of Environment and Genes Related to Diseases, Xi'an Jiaotong University, Ministry of Education, Xi'an, Shaanxi 710061, P.R. China

E-mail: hchen@mail.xjtu.edu.cn

*Contributed equally

Key words: interferon-like response, targeting response, MAPK p42, RNA interference
siRNA and up-regulation by U0126 were noted. The results of real-time quantitative PCR showed that P38 was up-regulated and NUP188 was down-regulated by siRNA in comparison with the control groups, and the results were consistent with those of U0126. Expression levels of STAT1, STAT2, PML and OAS1 induced by siRNA differed from those induced by U0126. siRNA-mediated silencing and deactivation induced by U0126 in MAPK p42 led to growth inhibition in the HeLa cells. The effects of siRNA on HeLa cell growth were different from those of U0126. Dual effects of MAPK p42 siRNA-2 on HeLa cell growth were noted: one consisted of a specific effect induced by siRNA-mediated p42 MAPK silencing and the other exhibited a non-specific interferon-like response.

\section{Introduction}

RNA interference (RNAi) is a natural protective mechanism that functions in various organisms (1-4). Small-interfering RNAs (siRNAs) (21-23 nt) are thought to be generated from stretches of double-stranded RNA by Dicer, a conserved member of the RNase III gene family. siRNAs are then incorporated into a large multiprotein RNA-inducing silencing complex. In the siRNA-mediated mRNA degradation pathway, the antisense strand of the siRNA molecule is used to target the cognate mRNA for degradation. This process involves specific base pairing between the antisense strand of the siRNA and the target mRNA, endonucleolytic cleavage of the mRNA strand across the middle of the siRNA strand and subsequent degradation of the unprotected mRNA (5). RNAi provides a revolutionary tool to identify gene functions $(6,7)$ and opens new possibilities for therapeutic interventions (8-10). In early reports, $21 \mathrm{nt}$ siRNA was thought to be too small to activate PKR, a kinase that senses double-stranded RNA (11). However, other reports maintain that the transfection or expression of even short duplexes or hairpins is able to induce a subset of markers of innate immune response $(12,13)$.

The extracellular signal-regulated kinase (ERK)/MAPK pathway is constitutively active in several human malignancies, and it is critical for the induction of cell proliferation, differentiation and cell survival. Four major groups of MAPKs in mammalian cells are found: ERK, c-jun NH2-terminal kinase/stress-activated protein kinase, p38 and extracellular 
Table I. The primer sequences of eight genes for real-time quantitative PCR.

\begin{tabular}{|c|c|c|c|c|}
\hline Gene Bank no. & Gene & Primer sequence & $\begin{array}{l}\text { PCR product } \\
\text { length (bp) }\end{array}$ & $\begin{array}{l}\text { Temperature } \\
\left({ }^{\circ} \mathrm{C}\right)\end{array}$ \\
\hline NM_002534 & OAS1 & $\begin{array}{l}\text { Forward: 5'-CCAGGAAATTAGGAGACAGC-3' } \\
\text { Reverse: 5'-GAGCGAACTCAGTACGAAGC-3' }\end{array}$ & 165 & 88.0 \\
\hline NM_002675 & PML & $\begin{array}{l}\text { Forward: 5'-AGTCGGTGCGTGAGTTCCT-3' } \\
\text { Reverse: 5'-GGAACATCCTCGGCAGTAG-3' }\end{array}$ & 110 & 88.9 \\
\hline NM_015354 & NUP188 & $\begin{array}{l}\text { Forward: 5'-GCACTCTGCTGCTTATCC-3' } \\
\text { Reverse: 5'-CTTGGCCTTGGTCTTCTC-3' }\end{array}$ & 137 & 88.6 \\
\hline NM_139014 & p38 & $\begin{array}{l}\text { Forward: 5'-GCAGGAGCTGAACAAGACAATC-3' } \\
\text { Reverse: 5'-TTTCGCATGAATGATGGACTG-3' }\end{array}$ & 169 & 88.4 \\
\hline AA195999 & MAPK1 & $\begin{array}{l}\text { Forward: 5'-CCCAAATGCTGACTCCAAAGC-3' } \\
\text { Reverse: 5'-GCTCGTCACTCGGGTCGTAAT-3' }\end{array}$ & 131 & 84.8 \\
\hline ВC002704 & STAT1 & $\begin{array}{l}\text { Forward: 5'-TGCTCCTTTGGTTGAATCCC-3' } \\
\text { Reverse: 5'-GGAATTTTGAGTCAAGCTGCTG-3' }\end{array}$ & 92 & 90.7 \\
\hline NM_005419 & STAT2 & $\begin{array}{l}\text { Forward: 5'-GTGGTTCAGGAAAGGGCAG-3' } \\
\text { Reverse: 5'-GGAGGGTGTCCGTTTTCAG-3' }\end{array}$ & 123 & 87.9 \\
\hline NM_000094 & COL7A1 & $\begin{array}{l}\text { Forward: 5'-GTGTTGCTGCGTGACTTGG-3' } \\
\text { Reverse: 5'-AACAGAAGCGTCAGTGCGAG-3' }\end{array}$ & 114 & 90.3 \\
\hline NM_002046 & GAPDH & $\begin{array}{l}\text { Forward: 5'-AGTTAGCCGCATCTTCTTTTGC-3' } \\
\text { Reverse: 5'-CAATACGACCAAATCCGTTGACT-3' }\end{array}$ & 100 & 87.8 \\
\hline
\end{tabular}

signal regulated kinase-5 (ERK5, also known as Big MAP kinase-1) (14-17). ERK is mainly activated by mitogenic stimuli such as growth factors and hormones to induce cell proliferation. Previous studies showed that siRNA targeting for the MAPK p42 gene partially inhibits proliferation and increases apoptosis in human cervical carcinoma HeLa cells $(18,19)$. Results of a microarray analysis showed that MAPK p42 siRNA inhibited cell growth through the regulation of cell cycle control and apoptosis and induced an interferon-like response in HeLa cells (20). In order to confirm the specific effects of siRNA on MAPK p42 and the non-specific interferon-like response effect, the roles of siRNA and U0126, an inhibitor of MAPK p42, were compared in HeLa cells.

\section{Materials and methods}

siRNA synthesis. siRNAs were designed using RNAi target finder (http://www.ambion.com/techlib/misc/siRNA_finder. html). The two sets of siRNA sequences were: siRNA-1 (negative control) sense CUCUACGUAAGAUCCAGCUUU and antisense AGCUGGAUCUUACGUAGAGUU, bearing no homology with any known relevant human genes; and siRNA-2 sense AGCAAAUAGUUCCUAGCUUUU and antisense AAG CUAGGAACUAUUUGCUUU. siRNA were synthesized and purified by means of the Silencer ${ }^{\mathrm{TM}}$ siRNA Construction kit (Ambion, Austin, TX, USA).

Cell culture and transfection. Human HeLa cells (5.0x10 4 cells/ $\mathrm{ml})$ were cultured in RPMI-1640 supplemented with $10 \%(\mathrm{v} / \mathrm{v})$ fetal bovine serum containing $2.0 \mathrm{mmol} / \mathrm{l}$ glutamine and $20 \mu \mathrm{g}$ penicillin-streptomycin $/ \mathrm{ml}$ in $5 \% \mathrm{CO}_{2}$ at $37^{\circ} \mathrm{C}$, and allowed to adhere for $24 \mathrm{~h}$. HeLa cells were transfected by siRNA, using
Lipofectamine 2000 (Invitrogen) or treated with U0126 at different concentrations. Two days after transfection and treatment, cells were analyzed for MTT, cell cycle and real-time quantitative PCR. All tests were repeated five times.

MTT assay for cell viability. Cells (1.0x10\%/well) were cultured in 96-well plates. After $24 \mathrm{~h}$, the cells were incubated with siRNA for the indicated times at $37^{\circ} \mathrm{C}$ in $5 \% \mathrm{CO}_{2}$. Then, $20 \mu \mathrm{l} /$ well of MTT solution $(5 \mathrm{mg} / \mathrm{ml})$ was added, and cells were incubated for another $4 \mathrm{~h}$. The supernatants were removed, and formazan crystals were solubilized in $200 \mu \mathrm{l}$ of dimethylsulfoxide. Finally, optical density was determined at $490 \mathrm{~nm}$ by a POLARstar ${ }^{+}$Optima (BMG Labtechnologies).

Cell cycle analysis by flow cytometry. DNA content per duplicate was analyzed using a FACSCalibur FCM (BectonDickinson, Mountainview, CA, USA). The adherent cells were harvested by brief trypsinization, washed with PBS, fixed in $70 \%$ ethanol, stained with $20 \mu \mathrm{g} / \mathrm{ml}$ propidium iodide containing $20 \mu \mathrm{g} / \mathrm{ml}$ RNase (DNase-free) for $30 \mathrm{~min}$ and analyzed by flow cytometry. The populations of G0/G1, S and G2/M cells were quantified.

Real-time quantitative PCR using SYBR-Green I. The message RNA levels of seven genes, i.e., mitogen-activated protein kinase 1 (MAPK1), signal transducer and activator of transcription 1/2 (STAT1/2), cyclin-dependent kinase (PML), nucleoporin 188 (NUP188), 2',5'-oligoadenylate synthetase (OAS1) and p38 were measured in siRNA and control samples by real-time quantitative PCR (Table I). The reaction was performed using the ABI 7000 real-time PCR detection system (ABI PRISM, USA) with SYBR-Green I. 
A

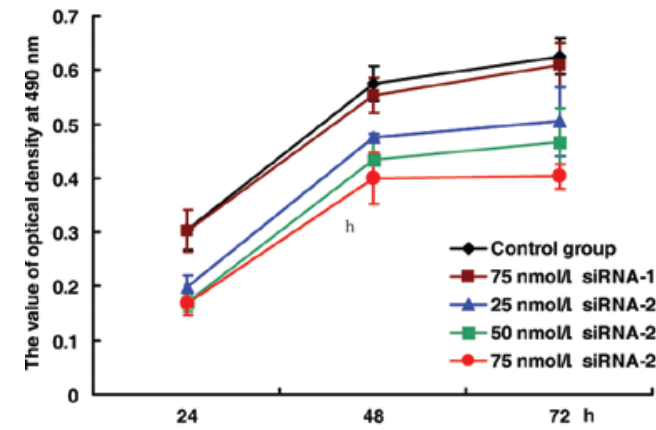

C

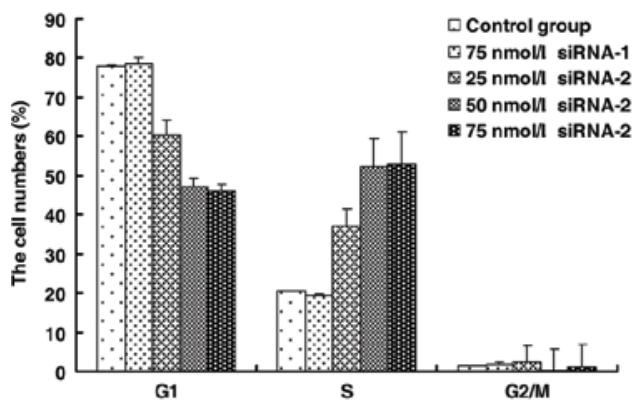

$\mathbf{E}$

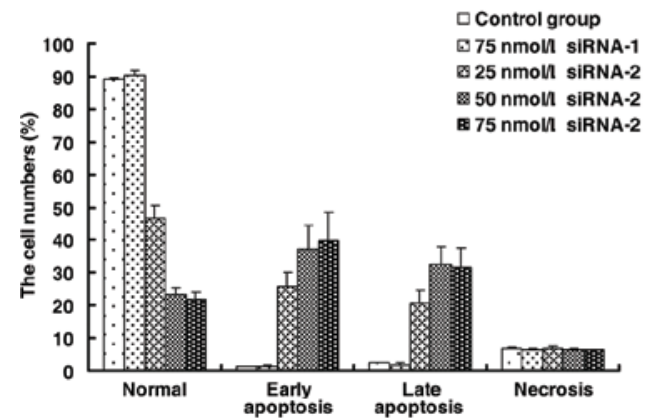

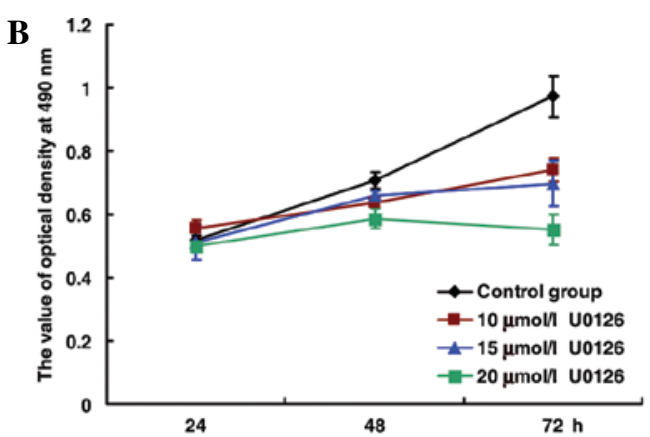
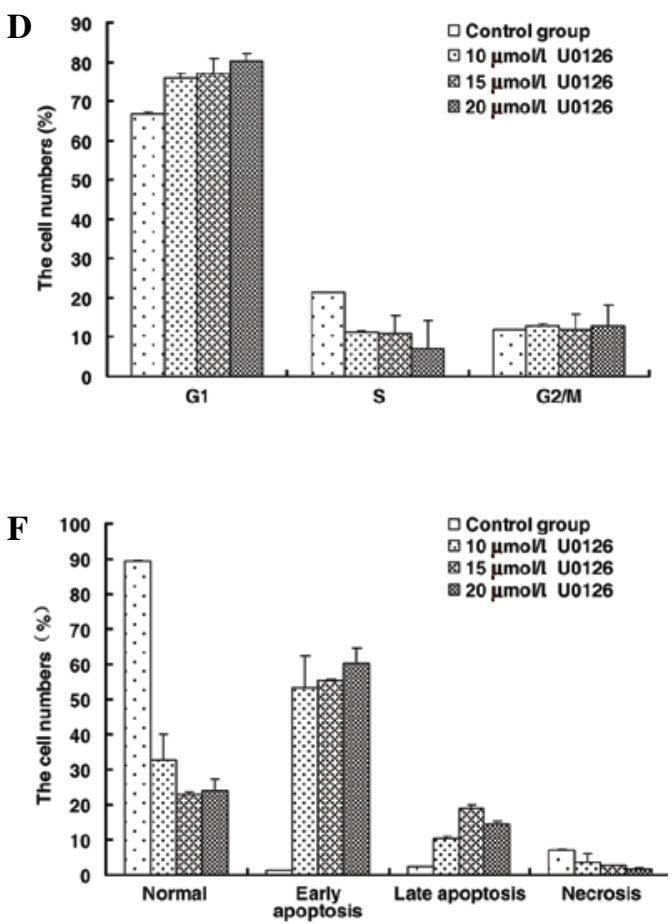

Figure 1. Inhibition of siRNA-2 and U0126 on cell growth in HeLa cells. Growth inhibition induced by (A) siRNA-2 and (B) U0126 treatment. Cell cycle arrest induced by (C) siRNA-2 and (D) U0126 treatment for $24 \mathrm{~h}$. Apoptosis induced by (E) siRNA-2 and (F) U0126 treatment for 24 h. Results are shown as the means $\pm \mathrm{SD}$ of five independent experiments.

Simultaneously, GAPDH was used in all of the specimens as the reference, and the quantitative analysis of message RNA levels was normalized by GAPDH. The fold change of the gene expression between siRNA and the control group was

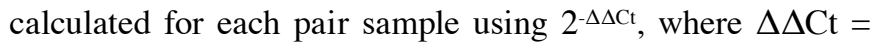
$\left(\mathrm{Ct}_{\text {gene }}-\mathrm{Ct}_{\mathrm{GAPDH}}\right)_{\text {siRNA }}-\left(\mathrm{Ct}_{\text {gene }}-\mathrm{Ct}_{\mathrm{GAPDH}}\right)_{\text {control }} \cdot 2^{-\Delta \Delta \mathrm{Ct}}>2$ was calculated to be gene overexpression (14).

Statistical analysis. Data were expressed as means \pm SD and analyzed by SPSS10.0 software. $\mathrm{P}<0.05$ was considered to be statistically significant.

\section{Results}

Effects of siRNA and U0126 on the inhibition of HeLa cell growth. HeLa cells were exposed to siRNA or U0126 at different concentrations at different times. U0126 significantly inhibited the growth of HeLa cells at certain concentrations (Fig. 1B), and the inhibition ratio of U0126 reached $17.1 \%$ at $20 \mu \mathrm{mol} / \mathrm{l}$ for $48 \mathrm{~h}$. In comparison with the control group and negative siRNA-1 (Fig. 1A), siRNA-2 was found to inhibit the proliferation of HeLa cells. The inhibition ratio of siRNA-2 reached the highest level of $\sim 30.4 \%$ at $75 \mathrm{nmol} / 1$ for $48 \mathrm{~h}$. The cell cycle of HeLa cells was arrested at the G1 phase by U0126 (Fig. 1C) and at the S phase by siRNA-2 (Fig. 1D). The effects of siRNA-2 were greater than those of U0126 on the apoptosis of HeLa cells in that U0126 induced early apoptosis (Fig. 1F), while siRNA-2 increased late apoptosis (Fig. 1E).

Effects of siRNA and U0126 on the expression of MAPK $p 42$, NUP188 and p38. To evaluate the effects of siRNA-2 on MAPK p 42 silencing, real-time quantitative PCR was used. The results showed that the expression of MAPK p42 was inhibited $\sim 60$ and $70 \%$, respectively, by siRNA-2 in comparison with the control group and negative siRNA-1 (Fig. 2A). By contrast, U0126 induced MAPK p42 expression (Fig. 2B). The results showed that inhibition of the MAPK p42 activity by U0126 led to an increase in MAPK p42 expression in compensation.

NUP188 was down-regulated and p38 was up-regulated by siRNA-2 and U0126. The consistency in the result between 
A

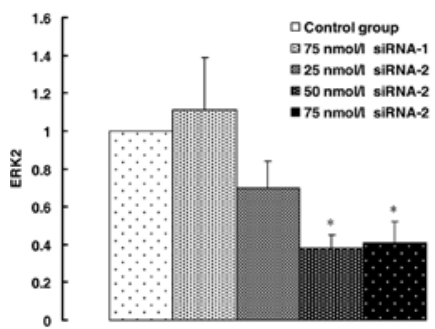

C

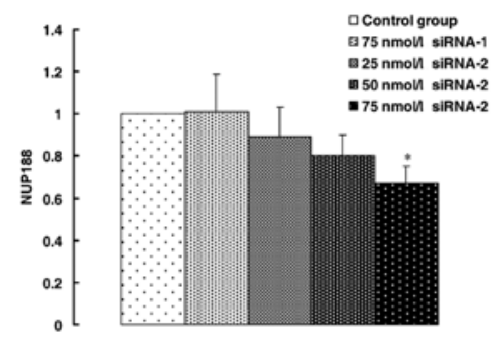

$\mathbf{E}$

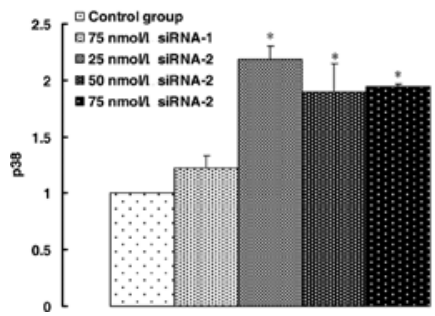

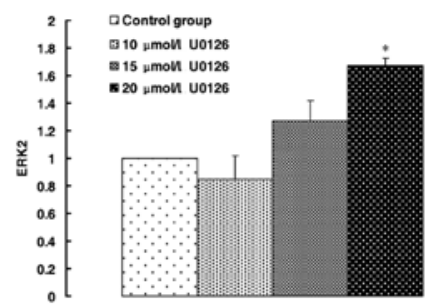

D

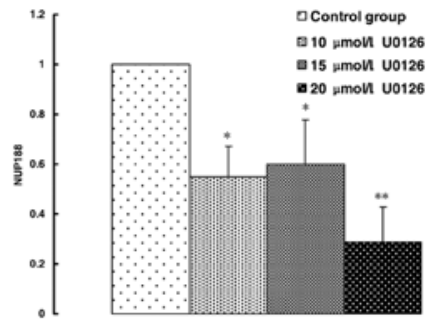

$\mathbf{F}$

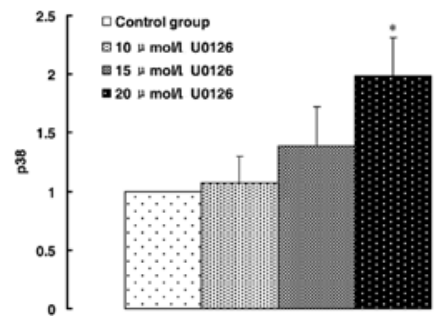

Figure 2. Effects of siRNA-2 and U0126 on the expression of ERK2, NUP188 and p38 in HeLa cells. ERK2 expression in HeLa cells treated with (A) siRNA and (B) U0126. NUP188 expression in HeLa cells treated with (C) siRNA and (D) U0126 in HeLa cells. The p38 expression in HeLa cells was treated with (E) siRNA and (F) U0126. Results are shown as the means \pm SD of three independent experiments. ${ }^{*} \mathrm{P}<0.05$ and ${ }^{* *} \mathrm{P}<0.01$ vs. the control group.

siRNA-2 and that of U0126 showed that the down-regulation or inhibition in MAPK p42 activity led specifically to the response of the expression in NUP188 (Fig. 2C and D) and p38 (Fig. 2E and F).

Effects of siRNA and U0126 on the expression of interferonlike response genes. The OAS1 gene is a member of the OAS family of interferon-induced antiviral enzymes. siRNA-2 and negative siRNA-1 induced the overexpression of OAS1 in HeLa cells in comparison with the control group (Fig. 3A); U0126 inhibited the expression of OAS1 (Fig. 3B). However, in addition to the treatment of siRNA- 2 at $25 \mathrm{nmol} / \mathrm{l}$, other siRNA-2 groups inhibited the expression of OAS1 in comparison with negative siRNA-1. The mode of expression of the PML gene was consistent with that of OAS1 induced by siRNA-2 (Fig. 3C). These results showed that the up-regulation of the expression in OAS1 and PML was a non-specific response to siRNA-2. STAT1 and STAT2 are involved in interferon (IFN) signaling pathways and play a key role in promoting apoptosis in a variety of cell types. STAT1 and STAT2 expression was slightly down-regulated by U0126 (Fig. 4B and D), but up-regulated significantly by siRNA-2 and negative siRNA-1 (Fig. 4A and C).

\section{Discussion}

The overexpression and activation of ERK has been documented in leukemia, renal cell carcinoma, breast cancer and several ovarian cancer cell lines (21-23). The suppression of MAPK p42 expression and activity by siRNA or U0126 resulted in the inhibition of HeLa cell growth. Results showed that MAPK p42 is involved in HeLa cell growth. Steinmetz et al also demonstrated that silencing of the ERK1/2 protein expression using RNAi led to the complete suppression of HeyC2 and SKOV3 cell proliferation (24). Tamemoto et al found that 44- and 42-kDa MAPKs exhib- 
A

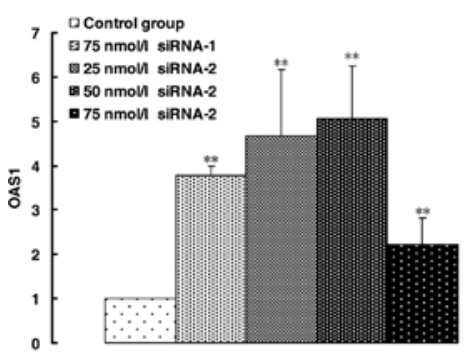

C

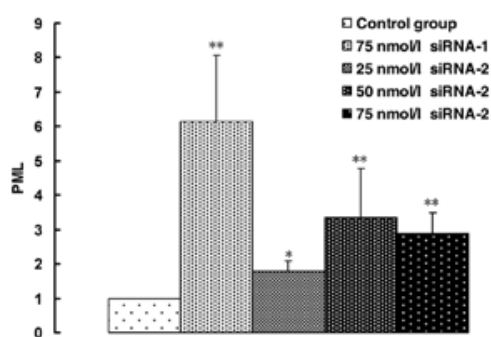

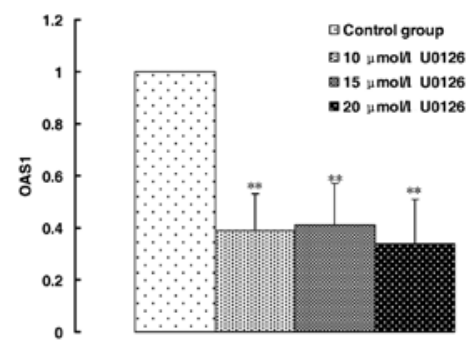

D

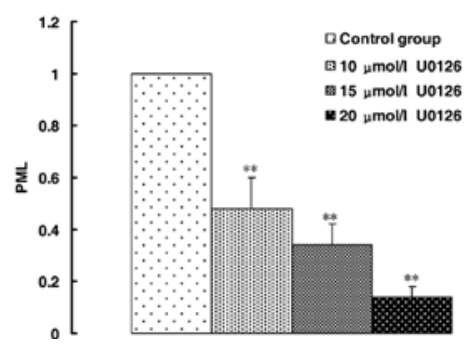

Figure 3. Effects of siRNA-2 and U0126 on the expression of the PML and OAS1 genes in HeLa cells. OAS1 expression caused by (A) siRNA and (B) U0126 treatment in HeLa cells. PML expression caused by (C) siRNA and (D) U0126 when applied in HeLa cells. Results are shown as the means \pm SD of three independent experiments. ${ }^{*} \mathrm{P}<0.05$ and ${ }^{* *} \mathrm{P}<0.01$ vs. control group.

A

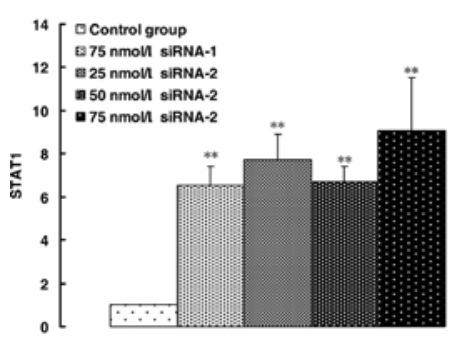

$\mathbf{C}$

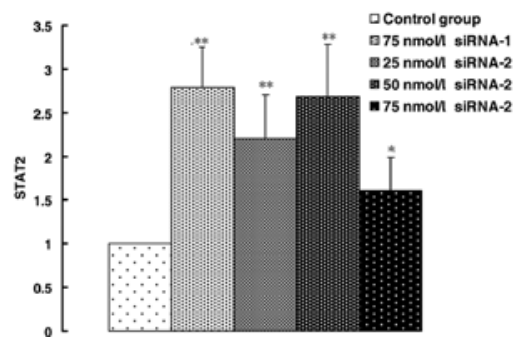

B

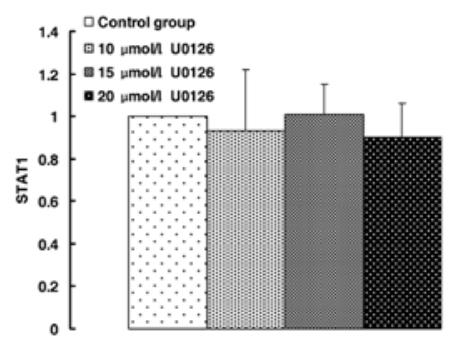

D

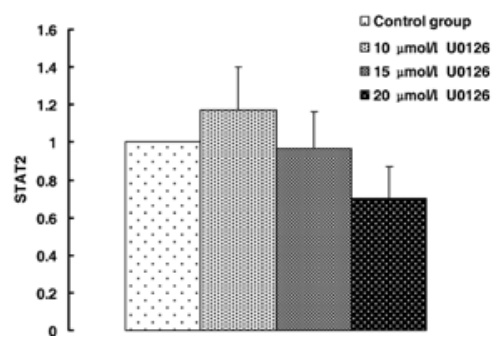

Figure 4. Effects of siRNA-2 and U0126 on the expression of STAT1 and STAT2 genes in HeLa cells. STAT1 expression caused by (A) siRNA and (B) U0126 treatment in HeLa cells. STAT2 expression caused by (C) siRNA and (D) U0126 treatment in HeLa cells. Results are shown as the means \pm SD of three independent experiments. ${ }^{*} \mathrm{P}<0.05$ and ${ }^{* *} \mathrm{P}<0.01$ vs. the control group.

ited activities in the G1 through $\mathrm{S}$ and $\mathrm{G} 2 / \mathrm{M}$ phases and were activated biphasically in the G1 phase and around the M phase (25). Our results showed that the cell cycle was arrested at the G1 phase by $\mathrm{U} 0126$ and at the S phase by
siRNA-2, suggesting different cell proliferation suppression effects between U0126 and siRNA-2.

The $21 \mathrm{nt}$ siRNA targeting MAPK p42 induced the downregulation of MAPK p42 in comparison with the control group 
and negative siRNA-1, while U0126 induced MAPK p42 expression, suggesting that siRNA-mediated silencing of the MAPK $\mathrm{p} 42$ gene was a specific effect of siRNA. A decrease in MAPK p42 occurred along with an increase in MAPK p38, another protein of the MAPK pathway $(26,27)$. This increase was thought to be responsible for the progression of apoptosis. Our results were similar in that the decrease in MAPK p42 expression induced by siRNA or the decrease in MAPK p42 activity induced by U0126 caused a slight increase in MAPK p38 expression (Fig. 2E and F). NUP188 is a type of nucleoporin (Nup). Approximately 30 types of Nup family nucleoside transporters can construct a nuclear pore complex in the membrane of a cell nucleus. This complex is an important component involved in the nucleocytoplasmic transport of biomacromolecules, but its mechanism remains unknown. NUP188 was down-regulated by siRNA-2 and U0126. The consistency between the result of siRNA-2 and U0126 showed that the down-regulation or inhibition of activity of MAPK p42 led particularly to a response of expression of NUP188 (Fig. 2C and D).

dsRNA structures greater than $30 \mathrm{bp}$ were found to stimulate the IFN pathway mediated in part by the activation of the dsRNA-dependent protein kinase R (PKR), which represented a host response to viral infection $(28,29)$. Several genes were activated in the IFN pathway, including the member of the OAS family, STAT1/2 and PML $(30,31)$. It was thought that 21 nt siRNAs were too short to induce interferon expression (12). It was possible to administer naked, synthetic siRNA to mice and down-regulate an endogenous or exogenous target without inducing an interferon response (32). However, previous studies found that the transfection of siRNA resulted in an interferon-mediated activation of the Janus kinase/STAT pathway and the global up-regulation of interferon-stimulated genes $(12,13,33)$. In order to confirm the interferon responses of siRNA-2, STAT1/2, PML and OAS1 were detected by realtime PCR. Differential effects of siRNA and U0126 on the expression of interferon-like response genes were noted. The inhibition of MAPK p42 activity by U0126 induced the downregulation of OAS1 and PML (Fig. 3B and D) in HeLa cells, but the knockdown of MAPK p42 by MAPK p42 siRNA caused the up-regulation of OAS1 and PML levels (Fig. 3A and $\mathrm{C}$ ), which were lower than those induced by negative siRNA. The effects of U0126 on the expression of STAT1 and STAT2 were slight (Fig. 4B and D) and MAPK p42 siRNA promoted the expression of STAT1 and STAT2 (Fig. 4A and C). PML, STAT1 and STAT2 were proven to be involved in the inhibition of cell growth (34-36).

In conclusion, MAPK p42 siRNA, not only specifically knocked down MAPK p42 and increased p38 expression in comparison with the small-molecule MEK inhibitor U0126, but also non-specifically stimulated the interferon responses which increased the expression of pro-apoptotic genes including PML, STAT1 and STAT2, ultimately triggering HeLa cell apoptosis. Our results suggest that siRNA-mediated down-regulation of MAPK p42 is an attractive strategy for cancer gene therapy.

\section{Acknowledgements}

This work was supported by the National Natural Science Foundation of China (30872481) and the Scientific and
Technological Planning Foundation of Shaanxi Province (2006K09-G7-1).

\section{References}

1. Lohmann JU, Endl I and Bosch TC: Silencing of developmental genes in Hydra. Dev Biol 214: 211-214, 1999.

2. Yang D, Lu H and Erickson JW: Evidence that processed small dsRNAs may mediate sequence-specific mRNA degradation during RNAi in Drosophila embryos. Curr Biol 10: 1191-1200, 2001.

3. Zhao Z, Cao Y, Li M, et al: A double-stranded RAN injection produces nonspecific defects in zebrafish. Dev Biol 229: 215-223, 2001.

4. Wianny F and Zernicka-Goetz M: Specific interference with gene function by double-stranded RNA in early mouse development. Nat Cell Biol 2: 70-75, 2000.

5. Fire A, Xu S, Montgomery MK, et al: Potent and specific genetic interference by double-stranded RNA in Caenorhabditis elegans. Nature 391: 806-811, 1998.

6. Quon K and Kassner PD: RNA interference screening for the discovery of oncology targets. Expert Opin Ther Targets 13: 1027-1035, 2009.

7. Varambally S, Dhanasekaran SM, Zhou M, Barrette TR, Kumar-Sinha C, Sanda MG, Ghosh D, Pienta KJ, Sewalt RG, Otte AP, Rubin MA and Chinnaiyan AM: The polycomb group protein EZH2 is involved in progression of prostate cancer. Nature 419: 624-629, 2002.

8. Rodríguez-Lebrón E, Gouvion CM, Moore SA, Davidson BL and Paulson HL: Allele-specific RNAi mitigates phenotypic progression in a transgenic model of Alzheimer's disease. Mol Ther 17: 1563-1573, 2009.

9. Courties G, Presumey J, Duroux-Richard I, Jorgensen C and Apparailly F: RNA interference-based gene therapy for successful treatment of rheumatoid arthritis. Expert Opin Biol Ther 9: 535-538, 2009.

10. Pfister EL, Kennington L, Straubhaar J, Wagh S, Liu W, DiFiglia M, Landwehrmeyer B, Vonsattel JP, Zamore PD and Aronin N: Five siRNAs targeting three SNPs may provide therapy for three-quarters of Huntington's disease patients. Curr Biol 19: 774-778, 2009.

11. Paddison PJ, Caudy AA and Hannon GJ: Stable suppression of gene expression by RNAi in mammalian cells. Proc Natl Acad Sci USA 99: 1443-1448, 2002.

12. Bridge AJ, Pebernard S, Ducraux A, Nicoulaz AL and Iggo R: Induction of an interferon response by RNAi vectors in mammalian cells. Nat Genet 34: 263-264, 2003.

13. Sledz CA, Holko M, de Veer MJ, Silverman RH and Williams BR: Activation of the interferon system by short-interfering RNAs. Nat Cell Biol 5: 834-839, 2003.

14. Boulton TG, Nye SH, Robbins DJ, et al: ERKs: a family of protein-serine/threonine kinases that are activated and tyrosine phosphorylated in response to insulin and NGF. Cell 65: 663-675, 1991.

15. Derijard B, Hibi M, Wu IH, et al: JNK1: a protein kinase stimulated by UV light and Ha-Ras that binds and phosphorylates the c-Jun activation domain. Cell 76: 1025-1037, 1994.

16. Han J, Lee JD, Bibbs L, et al: A MAP kinase targeted by endotoxin and hyperosmolarity in mammalian cells. Science 265: 808-811, 1994.

17. Kyriakis JM and Avruch J: Mammalian mitogen-activated protein kinase signal transduction pathways activated by stress and inflammation. Physiol Rev 81: 807-869, 2001.

18. Huang C, Liu LY, Song TS, et al: Small interfering RNA-mediated MAPK p42 silencing induces apoptosis of HeLa cells. Nan Fang Yi Ke Da Xue Xue Bao 26: 11-15, 2006.

19. Liu L, Huang C, Li Z, et al: Related genes for HeLa cell apoptosis induced by siRNA-mediated MAPK p42 silencing. Acta Med Univ Sci Technol Huazhong 37: 129-132, 2008.

20. Huang C, Liu L, Li Z, et al: Effects of small interfering RNAs targeting MAPK1 on gene expression profile in HeLa cells as revealed by microarray analysis. Cell Biol Int 32: 1081-1090, 2008.

21. Staber PB, Linkesch W, Zauner D, Beham-Schmid C, Guelly C, Schauer S, Sill H and Hoefler G: Common alterations in gene expression and increased proliferation in recurrent acute myeloid leukemia. Oncogene 23: 894-904, 2004. 
22. Huang D, Ding Y, Luo WM, Bender S, Qian CN, Kort E, Zhang ZF, van den Beldt K, Duesbery NS, Resau JH and Teh BT: Inhibition of MAPK kinase signaling pathways suppressed renal cell carcinoma growth and angiogenesis in vivo. Cancer Res 68: 81-88, 2008.

23. Salh B, Marotta A, Matthewson C, Ahluwalia M, Flint J, Owen D and Pelech S: Investigation of the Mek-MAP kinase-Rsk pathway in human breast cancer. Anticancer Res 19: 731-740, 1999.

24. Steinmetz R, Wagoner HA, Zeng P, Hammond JR, Hannon TS, Meyers JL and Pescovitz OH: Mechanisms regulating the constitutive activation of the extracellular signal-regulated kinase (ERK) signaling pathway in ovarian cancer and the effect of ribonucleic acid interference for ERK1/2 on cancer cell proliferation. Mol Endocrinol 18: 2570-2582, 2004.

25. Tamemoto H, Kadowaki T, Tobe K, Ueki K, Izumi T, Chatani Y, Kohno M, Kasuga M, Yazaki Y and Akanuma Y: Biphasic activation of two mitogen-activated protein kinases during the cell cycle in mammalian cells. J Biol Chem 267: 20293-20297, 1992.

26. Bradham C and McClay DR: p38 MAPK in development and cancer. Cell Cycle 5: 824-828, 2006.

27. Parameswaran N, Nambi, P, Hall CS, Brooks DP and Spielman WS: Adrenomedullin decreases extracellular signal-regulated kinase activity through an increase in protein phosphatase-2A activity in mesangial cells. Eur J Pharmacol 388: 133-138, 2000

28. Sen GC: Viruses and interferons. Annu Rev Microbiol 55: 255-281, 2001

29. Saunders LR and Barber GN: The dsRNA binding protein family: critical roles, diverse cellular functions. FASEB J 17: 961-983, 2003
30. Hovanessian AG and Justesen J: The human 2'-5'oligoadenylate synthetase family: unique interferon-inducible enzymes catalyzing 2'-5' instead of 3'-5' phosphodiester bond formation. Biochimie 89: 779-788, 2007.

31. Boese A, Sommer P, Gaussin A, Reimann A and Nehrbass U: Inil/hSNF5 is dispensable for retrovirus-induced cytoplasmic accumulation of PML and does not interfere with integration. FEBS Lett 578: 291-296, 2004.

32. Heidel JD, Hu S, Liu XF, Triche TJ and Davis ME: Lack of interferon response in animals to naked siRNAs. Nat Biotechnol 22: 1579-1582, 2004.

33. Sledz CA and Williams BR: RNA interference and doublestranded-RNA-activated pathways. Biochem Soc Trans 32: 952-956, 2004

34. Lapi E, Di Agostino S, Donzelli S, Gal H, Domany E, Rechavi G, Pandolfi PP, Givol D, Strano S, Lu X and Blandino G: PML, YAP, and p73 are components of a proapoptotic autoregulatory feedback loop. Mol Cell 32: 803-814, 2008

35. Youlyouz-Marfak I, Gachard N, Le Clorennec C, Najjar I, Baran-Marszak F, Reminieras L, May E, Bornkamm GW, Fagard R and Feuillard J: Identification of a novel p53-dependent activation pathway of STAT1 by antitumour genotoxic agents. Cell Death Differ 15: 376-385, 2008.

36. Negoro S, Kunisada K, Tone E, et al: Activation of JAK/STAT pathway transduces cytoprotective signal in rat acute myocardial infarction. Cardiovasc Res 47: 797-805, 2000. 